\title{
EVALUASI PEMANFAATAN JURNAL DALAM DATABASE "EBSCO BIOMEDICAL REFERENCE COLLECTION" DI UNIT PERPUSTAKAAN DAN INFORMATIKA KEDOKTERAN (UPIK) FAKULTAS KEDOKTERAN UGM YOGYAKARTA
}

\author{
Disusun Oleh: \\ Eka Wardhani S. dan Drs. Purwono, MSi
}

\section{INTISARI}

Evaluasi terhadap pemanfaatan koleksi sangat diperlukan untuk mengetahui seberapa besar koleksi tersebut diakses dan dimanfaatkan oleh pengguna. Ebsco Biomedical Reference Collection (Ebsco BRC) merupakan salah satu database jurnal yang berparadigma akses. Evaluasi pemanfaatan jurnal dalam database Ebsco BRC merupakan penelitian tentang pemanfaatan koleksi perpustakaan yang dilakukan di UPIK (Unit Perpustakaan dan Informatika Kedokteran) Fakultas Kedokteran Universitas Gadjah Mada Yogyakarta. Penelitian ini bertujuan untuk mengetahui tingkat keterpakaian dan pemanfaatan jurnal oleh sivitas akademika di FK UGM. Evaluasi dilakukan dengan metode deskriptif dengan pendekatan data kuantitatif dan kualitatif. Instrumen yang digunakan dalam evaluasi adalah kuesioner dan usage statistics report. Hasil Penelitian ini menunjukkan bahwa tingkat keterpakaian jurnal berdasarkan judul yang ada tinggi $(97,96 \%)$, akan tetapi tingkat pengaksesannya belum dilakukan secara maksimal. Rata-rata pengaksesan jurnal setiap harinya $25 \%$. Dari data usage statistics report dapat diketahui sebanyak 12 judul jurnal yang diakses lebih dari 1000 kali yang dinyatakan sebagai jurnal yang paling sering diakses oleh pengguna. Saran peneliti berdasarkan hasil penelitian yang diperoleh adalah bahwa kegiatan melanggan koleksi database Ebsco dapat terus dilakukan, akan tetapi UPIK harus berusaha meningkatkan sosialisasi koleksi, aksesibilitas, fasilitas, dan bimbingan bagi pengguna dalam melakukan penelusuran dalam database tersebut agar dapat dimanfaatkan secara maksimal.

Kata Kunci: Evaluasi Koleksi, Ebsco

\section{ABSTRACT}

The impact of the information technology to libraries changes the library collection paradigm. The change of the paradigm can be seen from ownership to accessibility. Therefore evaluation collection evaluation becomes important in order to know the accessibility and the use of the collection in the Ebsco Biomedical Reference Collection (Ebsco BRC) which is in a journal databases at the Unit Perpustakaan dan Informatika Kedokteran (UPIK) Medical Faculty of Gadjah Mada University Yogyakarta. The purpose of this research is to know the level of use of the journal, the core journal and mathces of the journal to the medical faculty department. Besides the research is hoped to contribute to the collection development of the UPIK and to increase the use of the collection uses. The study employs qualitative and quantitative descriptive methods and its instrument uses questionaire and the papersheet of the journal distribution as well as statistic reports available in Ebscohost. The result of this research shows that the number of accesses to the journal is 865 from 883 titles $(97,96 \%)$, The frequency of the journal acesses is 80333 in 2005 . The access to the journal averages $25 \%$ /days. Furthermore the statistic reports demonstrate that the core of the journal is 12 titles with more than 1000 acesses. The number of the journal core will reach 25 titles if we include the accessing between 500-1000. Fifty six percent respondents that stated that the content of the journal has matched with their study program. The result mean that the UPIK should keep subscribing Ebsco BRC database.

Keyword: Collection evaluation, Ebsco Database Journal 


\section{PENDAHULUAN}

Pada awal perkembangan teknologi informasi masuk ke perpustakaan, teknologi ini banyak membantu dalam pembuatan database systems dan sistem temu kembali informasi. Akan tetapi dalam kenyataannya beberapa pengguna merasa tidak terpuaskan kebutuhannya dengan penyajian daftar sitasi (indeks) atau petunjuk bagaimana menggunakan katalog. Pengguna telah berubah keinginannya dari pengamat menjadi konsumen aktif terhadap layanan informasi yang ditawarkan (Thompson, 1982:101). Hal ini tentunya membuka paradigma baru bagi pustakawan bahwa yang diinginkan pengguna adalah sebuah informasi yang benar-benar sesuai dengan kebutuhan mereka. Sehubungan dengan hal itu perlu adanya pengawasan terhadap koleksi dan pemanfaatannya agar kesestuaian koleksi dengan pengguna dapat selalu diketahui. Salah satu cara pengawasan yang bisa dilakukan adalah dengan melakukan evaluasi pemanfaatan koleksi perpustakaan.

Evaluasi pemanfaatan koleksi juga penting untuk menjaga kualitas pelayanan perpustakaan terhadap pengguna. Sebuah penelitian di United Kingdom menyatakan bahwa hubungan antara perubahan koleksi dengan layanan adalah berbanding lurus. Pada waktu koleksi meningkat 79\% akademisi menyatakan bahwa pelayanan yang diberikan juga meningkat. Begitu juga ketika mereka meningkatkan pelayanan perpustakaan maka $70 \%$ pengguna mengatakan bahwa koleksi perpustakaan itu lebih baik (Evens, 1996:80). Hal ini menunjukkan bahwa perbaikan koleksi perpustakaan juga akan meningkatkan image pustakawan dan perpustakaan terhadap penggunanya.
Koleksi jurnal dalam database online Ebsco Biomedical Reference collection yang dilanggan oleh UPIK Fakultas Kedokteran UGM merupakan salah satu jenis koleksi yang dilayankan seperti halnya koleksi tercetak. Disana juga disediakan komputer (PC Client) untuk pengaksesannya dan untuk pengaksesan tersebut pengguna tidak dikenakan biaya tambahan. Hal itulah yang menjadi pertimbangan utama bagi peneliti untuk memilih database Ebsco yang dilanggan oleh UPIK sebagai objek penelitian daripada yang di tempat lain. Evaluasi pemanfaatan jurnal dalam database Ebsco Biomedical Reference collection perlu dilakukan untuk mengetahui efektifitas koleksi tersebut. Lebih lanjut lagi evaluasi diharapkan dapat memberikan gambaran tentang tingkat keterpakaian jurnal, pemanfaatan jurnal oleh pengguna, dan jurnal yang paling sering diakses oleh pengguna.

Berdasarkan data usage statistics report keterpakaian jurnal sebanyak 865 judul dan pengaksesan sebanyak 80333 kali selama tahun 2005. Berdasarkan data tersebut juga diperoleh data tentang core jurnal yang dipakai oleh pengguna di Fakultas Kedokteran UGM. Core jurnal tersebut ditentukan berdasarkan frekuensi penggunaannya yang diketahui melalui usage statistics report dan dilihat kesesuaiannya dengan kebutuhan pengguna.

Berdasarkan latar belakang yang telah diuraikan tersebut, maka rumusan masalah dalam penelitian ini adalah sebagai berikut :

1. Bagaimana tingkat keterpakaian dan pemanfaatan jurnal dalam database Ebsco BRC oleh penggunanya?

2. Apakah core jurnal yang dipakai oleh sivitas akademika Fakultas Kedokteran 
UGM yang dilanggan melalui jurnal Biomedical Reference Collection dari basisdata online Ebsco sesuai dengan kebutuhan pengguna?

Dalam penelitian ini peneliti membatasi objek yang diteliti hanyalah database online Ebsco BRC yang dilanggan pada tahun 2005 oleh Unit Perpustakaan dan Informatika Fakultas Kedokteran UGM Yogyakarta. Oleh karena itu hasil dari penelitian ini hanya berlaku bagi koleksi jurnal dalam database Ebsco yang ada di Fakultas Kedokteran UGM, tidak berlaku di tempat lain.

\section{TINJAUAN PUSTAKA}

Evaluasi pemanfaatan majalah ilmiah pernah dilakukan Ishak pada tahun 2001 dengan mengambil subjek penelitian Pusat Informasi Kedokteran (Medical Information centre) PT. Squibb Indonesia. Penelitian pemanfaatan koleksi lainnya yang menggunakan metode deskriptif kuantitatif juga pernah dilakukan oleh Farli Elnumeri tahun 2002. Penelitian ini menggunakan Perpustakaan Pramuka Ki Hajar Dewantara sebagai subjek penelitian dan koleksi buku teks sebagai objek yang diteliti.

Penelitian tentang evaluasi koleksi lainnya juga pernah dilakukan oleh Wisnu Hardi. Penelitian ini bertujuan untuk mengetahui distribusi koleksi perpustakaan dalam mendukung koleksi inti perpustakaan. Dengan menggunakan metode conspectus secara deskriptif penelitian ini mengungkapkan kelemahan dan kekuatan koleksi yang ada di Perpustakaan FIB UI Jakarta.

Dari ketiga tinjauan pustaka yang diuraikan diatas dapat disimpulkan bahwa penelitian tentang evaluasi pemanfaatan koleksi banyak dilakukan dengan metode deskriptif. Pendekatan yang digunakan dapat dilakukan secara kuantitatif ataupun kualitatif. Secara kuantitatif pemanfaatan koleksi bisa diketahui dari prosentase penggunaan koleksi tersebut terhadap keseluruhan koleksi. Secara kualitatif, evaluasi koleksi bisa diketahui dengan melihat distribusi koleksi terhadap standar koleksi yang ada atau dengan membandingkan dengan koleksi yang sama di tempat lain.

\section{PARADIGMA KOLEKSI PERPUSTAKAAN DAN PENGERTIAN DATABASE ONLINE}

Salah satu strategi yang dapat disarankan untuk menuju perpustakaan pada era globalisasi serta dapat berperan maksimal adalah menyediakan koleksi baik tercetak maupun elektronik yang bermutu (worldclass) dan perpustakaan harus menggunakan teknoiogi yang adaptif (Ratnaningsih, 1998:20). Pemikiran ini sejalan dengan pendapat Arief S. Sadiman masih dalam sumber yang sama yang menyatakan bahwa salah satu variasi penggolongan fungsi perpustakaan sebagai pusat sumber belajar adalah pelayanan media. Hal ini berarti bahwa selain isi bahan pustaka harus sesuai dengan kebutuhan pemakai perpustakaan juga harus manyesuaikan dengan perkembangan teknologi informasi yang acapkali sudah melesat jauh ke depan dan pengguna pun sudah familiar dengan hal itu.

Dampak dari infasi teknologi informasi pada koleksi perpustakaan adalah munculnya koleksi elektronik dan koleksi digital. Koleksi ini ada yang berbentuk buku elektronik, compact Disc (CD), disket dan juga database online. Database (Online) adalah informasi digital (rekaman bibliografi, abstrak, dokumen fulltext, 
entri-entri direktori, gambar, statistik, dll) dalam jumlah yang besar dan selalu diperbaharui mengenai subjek tertentu, berisi rekaman dalam format yang seragam dan terorganisir agar mudah ditelusur dan ditemukan kembali dan disusun dengan system manajemen database (Database Management System). Isinya dibuat oleh produsen database, yang biasanya diterbitkan dalam versi tercetak dan ada beberapa yang berasal dari satu/lebih vendor database yang menyediakan akses elektronik yang sudah dikonversi ke bentuk terbacakan mesin, biasanya dalam bentuk CD_ROM atau online melalui internet dengan perangkat lunak untuk penelusurannya (Reitz, 2006:3).

Munculnya koleksi elektronik ini merubah paradigma perpustakaan dalam memandang koleksi. Karena yang terpenting adalah tingkat kemanfaatan / kegunaan koleksi yang dapat diketahui dari aksesibilitas database tersebut. Sehinga pada saat ini prestasi perpustakaan bukan lagi diukur berdasarkan kekayaan koleksi dan jumlah pengunjung yang datang langsung ke perpustakaan melainkan dari jumlah orang yang menggunakan layanan perpustakaan tersebut meskipun mereka tidak datang secara fisik (Mustafa, 1998:177)

Koleksi Database online biasanya dilanggan oleh perpustakaan melalui satu provider yang khusus menyediakan database dalam bentuk online. Pengadaan database ini biasanya membutuhkan biaya yang tidak sedikit. Fasilitas yang dibutuhkan untuk mengakses database inipun tidàk murah karena untuk mengakses database ini perpustakaan harus terhubung dengan saluran internet dan mempunyai jaringan yang luas untuk dapat mengoptimalkan pemanfaatannya. Sebagaimana telah disebutkan dalam pedoman evaluasi koleksi yang dikeluarkan oleh IFLA bahwa dalam evaluasi koleksi, sumber-sumber elektronik akan ekuivalen dengan bahan tercetak jika:

1. Akses pada sumber elektronik tersebut hampir sama dengan jurnal tercetak

2. Ada terminal-terminal untuk pengaksesan sumber-sumber elektronik tersebut dalam jumlah yang cukup

3. Pengguna tidak dikenakan tambahan biaya dalam pengaksesannya (IFLA, 2001:7)

\section{PENGERTIAN EVALUASI PEMANFAATAN KOLEKSI \& PENGUKURANNYA}

Evaluasi koleksi adalah penilaian yang dilakukan secara sistematis pada kualitas koleksi perpustakaan untuk pengembangannya yang mencakup kesesuaian antara tujuan umum dan tujuan khusus perpustakaan dengan kebutuhan informasi pengguna (Reitz, 2006: 54). Sedangkan kata pemanfaatan dapat diartikan sebagai proses, cara, perbuatan memanfaatkan (Kamus Besar Bahasa Indonesia 2002:711). Dari Dua kata ini kita bisa mendefinisikan evaluasi pemanfaatan koleksi sebagai penilaian terhadap kualitas koleksi yang telah dimanfaatkan oleh pengguna dan bagaimana koleksi tersebut digunakan. Terkait dengan pemanfaatan jurnal online, pemanfaatan disini bisa berarti material use dan material access.

Material use menunjukkan frekuensi penggunaan koleksi, sedangkan material access merupakan prosentase koleksi tersebut dilihat bisa melalui judul, subjek, pengarang, dan 
penelusuran yang benar-benar bisa didapatkan. (Bhisop, 2006:5). Dalam database Ebsco BRC material use ditunjukkan dengan data-data frekuensi pengguna dalam melakukan download jurnal dan bentuk-bentuk pemanfaatan jurnal tersebut oleh pengguna, misalnya dilihat saja atau didownload, atau digunakan untuk referensi dsb. Material access didapatkan dari penghitungan prosentase koleksi tersebut dilihat berdasarkan pengaksesan oleh pengguna dalam bentuk: PDF Fulltext, HTML Fulltext, Smart Link dan Abstract.

Evaluasi pemanfaatan koleksi di perpustakaan sangat penting dilakukan untuk mengetahui apakah koleksi yang dimiliki oleh pepustakaan memberikan kontribusi yang maksimal terhadap pemenuhan kebutuhan informasi pengguna. Tujuan evaluasi koleksi adalah untuk melihat secara nyata kemantapan kegunaan koleksi dan efektivitas koleksi tersebut, sehingga dapat memuaskan kebutuhan pengguna saat ini (Law, 1991:1). Beberapa tipe penelitian dalam pemanfaatan koleksi antara lain studi sirkulasi, survey pendapat pengguna dan penelitian ketersediaan koleksi (Gorman, 1989:135).

Pengevaluasian koleksi perpustakaan paling tidak ada 6 kategori yang akan menjadi tolak ukur efektivitas koleksi yaitu: aksesibilitas, anggaran, kepuasan pengguna, kecepatan temu kembali, perhitungan untung rugi, dan penggunaan (Evans, 1995:405). Penilaian koleksi akan mencapai keakuratan dan menghasilkan sesuatu yang berguna jika menggabungkan teknik atau pendekatan dari pengguna maupun dari segi koleksinya, termasuk pengumpulan data dan proses deskripsi secara kualitatif maupun kuantitatif
(IFLA 2001:4). Sementara itu Lancaster (1980) seperti dikutip oleh Wisnu Hardi (2005:35) menekankan pentingnya pengukuran evaluasi koleksi melalui frekuensi penggunaannya daripada perhatian pada koleksi itu sendiri. Metode ini melihat siapa saja yang menggunakan, tujuan pemanfaatan koleksi dan bagaimana koleksi yang sering digunakan.

Frekuensi penggunaan koleksi memang dapat digunakan untuk mengukur tingkat keterpakaian koleksi. Akan tetapi data ini tidak dapat digunakan untuk menginterpretasikan nilai koleksi. Karena itu, perlu ada data lain tentang nilai koleksi yang dapat melengkapi data yang diperoleh dari frekuensi pemanfaatan koleksi tersebut. Data tersebut dapat diperoleh dari survei pada pengguna tentang koleksi tersebut dan juga dengan mendistribusikan koleksi pada kurikulum fakultas yang bersangkutan. Dalam hal ini distribusi jurnal dapat dilakukan secara fleksibel. Artinya ada indikator lain yang dapat digunakan sebagai patokan selain kurikulum diantaranya adalah program studi yang ditawarkan oleh fakultas yang bersangkutan. Pemanfaatan koleksi juga dapat dioptimalkan penggunaannya jika koleksi tersebut sesuai dengan program studi yang ada di fakultas. Dengan adanya kesesuaian jurnal dengan program studi, diharapkan jurnal tersebut dapat mendukung mata kuliah di program studi yang terkait. Dua asumsi dasar yang penting pada evaluasi berdasarkan pengguna adalah:

1. Kecukupan koleksi yang secara langsung berhubungan dengan mahasiswa dan fakultas

2. Rekaman/data sirkulasi menyediakan gambaran yang dapat dipertanggung- 
jawabkan tentang penggunaan koleksi (Evans, 1995:418)

Koleksi yang dimaksud dalam point 1 diatas mengacu pada sumber informasi yang dapat dipergunakan sebagai referensi oleh pengguna yang bisa berupa buku, jurnal, majalah, prosiding dll. Dalam konteks penelitian ini koleksi yang dimaksud adalah jurnal Biomedical Reference Collection yang dilanggan melalui database EBSCO dengan cara online oleh UPIK Fakultas Kedokteran UGM.

Berdasarkan paparan teori yang telah diuraikan di atas penulis merasa perlu untuk mengevaluasi pemanfaatan koleksi berdasarkan dua data yaitu kuantitatif dan kualitatif. Data kuantitatif akan menunjukkan kecukupan koleksi baik terhadap pengguna maupun terhadap program studi yang ditawarkan, sedangkan data kualitatif dapat menginterpretasikan nilai koleksi tersebut baik terhadap pengguna maupun terhadap lembaga tempat koleksi tersebut berada. Kedua data ini akan saling melengkapi untuk mendapatkan hasil evaluasi yang optimal sehinga dapat digunakan sebagai masukan dalam pengambilan kebijakan terhadap koleksi itu sendiri.

Komponen yang akan dievaluasi dalam pemanfaatan koleksi jurnal Ebsco Biomedical Reference Collection meliputi: jurnal itu sendiri, aksesibilitas, penggunaan, penguasaan teknologi informasi dan fasilitas. Komponenkomponen ini digunakan sebagai dasar dalam pembuatan kuesioner untuk pengevaluasiannya. Evaluasi pemanfaatan jurnal ini dilakukan pada jurnal yang telah digunakan dan juga pada penguna jurnal tersebut sehingga akan dapat diketahui tingkat keterpakaian jurnal, pemanfaatan jurnal, dan kesesuaian jurnal tersebut terhadap program studi di Fakultas Kedokteran UGM.

\section{METODOLOGI PENELITIAN}

Dalam Penelitian ini subjek penelitian adalah mahasiswa Fakultas Kedokteran UGM yang terdiri dari jenjang pendidikan D4, S1 dan S2, sedangkan objek yang diteliti adalah jurnal di dalam database "EBSCO Medical Reference Collection" yang dilanggan oleh UPIK Fakultas Kedokteran UGM selama tahun 2005.

Tipe/jenis penelitian ini adalah penelitian deskriptif dengan pendekatan kuantitatif dan kualitatif. Metode deskriptif dapat diartikan sebagai prosedur pemecahan masalah yang diselidiki dengan menggambarkan/melukiskan keadaan subjek/ objek penelitian (seseorang, lembaga, masyarakat dan lain-lain pada saat sekarang berdasarkan fakta-fakta yang tampak atau sebagaimana adanya). (Nawawi, 2003: 63). Deskripsi data dalam penelitian ini berbentuk prosentase.

Penelitian ini merupakan penelitian dengan sampel dari total populasi yang ada. Populasi adalah keseluruhan objek penelitian (Arikunto, 2002: 108). Sedangkan sampel adalah sebagian atau wakil populasi yang diteliti (Arikunto, 2002: 109). Pengambilan sampel dilakukan dengan metode stratified proportional accidental sampling. Metode stratified proportional sampling digunakan pada populasi yang terbagi atas tingkat-tingkat atau strata, adanya strata ini tidak boleh diabaikan dan setiap strata harus diwakili sebagai sampel (Arikunto, 2002: 115). Accidental sampling menunjukkan pengambilan sampel yang 
didasarkan pada responden yang datang ke UPIK.

Total populasi yang ada sebanyak 4607 responden, sampel yang diambil sejumlah $10 \%$ dari total populasi yaitu sebanyak 461 responden. Pembagian sampel bertingkat diuraikan dalam tabel 1 sebagai berikut:

Tabed 1. Populasi dan Sampel Penelitian

\begin{tabular}{|c|c|c|c|c|}
\hline NO & POPULASI & JURUSAN & $\begin{array}{l}\text { JUMLAH } \\
\text { POPULASI }\end{array}$ & $\begin{array}{l}\text { JUMLAH } \\
\text { SAMPLL } \\
10 \% \times \text { poptulas }\end{array}$ \\
\hline \multirow[t]{4}{*}{1.} & \multirow{4}{*}{$\begin{array}{l}\text { Mahasiswa } \\
\text { Si }\end{array}$} & Pendidikan dokter & 1704 & $170,4=170$ \\
\hline & & & & \\
\hline & & PSIK & 700 & 70 \\
\hline & & PSGK & 311 & $3 \mathrm{I}, 1=31$ \\
\hline 2. & $\begin{array}{l}\text { Mahasiswa } \\
\text { program D4 }\end{array}$ & $\begin{array}{l}\text { Pend Bidan dan } \\
\text { perawat gigi }\end{array}$ & 123 & $12,3=12$ \\
\hline \multirow[t]{3}{*}{3.} & \multirow{3}{*}{$\begin{array}{l}\text { Mahasiswa } \\
\text { S2 }\end{array}$} & IKM & 1025 & $102,5=104$ \\
\hline & & PPDSI & 684 & $68,4=68$ \\
\hline & & IKD dan Biomedis & 60 & 6 \\
\hline & Total & & 4607 & $460,7=461$ \\
\hline
\end{tabular}

Tabel 2. Pengaksesan Ebsco Berdasarkan Judul Jurnal

\begin{tabular}{|c|c|c|c|}
\hline No & $\begin{array}{c}\text { Frekuensi } \\
\text { penggunaan }\end{array}$ & $\begin{array}{c}\text { Jumlah judul } \\
\text { jurnal }\end{array}$ & $\%$ \\
\hline 1 & $<100$ & 730 & 84,40 \\
\hline 2 & $100-500$ & 110 & 12,72 \\
\hline 3 & $500-1000$ & 13 & 1,50 \\
\hline 4 & $>1000$ & 12 & 1,38 \\
\hline & & 865 & 100 \\
\hline
\end{tabular}

Sumber: Olah data dari Usuge Statistics Fbsco BRC, Agustus 2006

Metode pengumpulan data dalam penelitian ini adalah metode survey dan dokumentasi. Instrumen yang digunakan dalam survey adalah kuesioner. Kuesioner ini digunakan untuk mengevaluasi koleksi dari sisi pengguna terhadap jurnal dalam Ebsco. Pengukuran skor untuk pertanyaan-pertanyaan yang diajukan dilakukan dengan menggunakan skala Likert. Cara pengukurannya adalah dengan menghadapkan seorang responden dengan sebuah pertanyaan kemudian diminta untuk memberikan jawaban "sangat tidak setuju", 'tidak setuju", "tidak berpendapat", "setuju","sangat setuju". Jawaban ini diberi skor 1-5 (Effendi, 1989:111).

Pengujian validitas dan reliabilitas instrumen dilakukan dengan mencobakan kuesioner pada 25 responden di UPIK FK UGM, pada tanggal 29 Juni 2006. Hasil uji validitas dan reliabilitas tersebut kuesioner dalam penelitian ini dinyatakan valid dan reliabel.

\section{HASIL \& PEMBAHASAN}

\section{A. Keterpakaian Jurnal Dalam Database Ebsco BRC}

Tingkat keterpakaian jurnal dapat diketahui dengan membandingkan antara judul jurnal yang pernah diakses dengan total jurnal dalam database Ebsco BRC. Dari data usage statistic Ebsco BRC tingkat keterpakaian jurnal secara keseluruhan 865 judul dari 883 judul yang ada. Prosentase keterpakaiannya sebesar 97,96\%. Hasil olah data interval pengaksesan jurnal Ebsco BRC berdasarkan data usage statistic adalah sebagai berikut:

Tabel 3. Pola Pengaksesan Ebsco BRC Berdasarkan Formatnya

\begin{tabular}{|c|c|c|c|c|}
\hline No & Format pengaksesan & Frekuensi & $\%$ & $\begin{array}{c}\text { Cum. } \\
\text { Percent }\end{array}$ \\
\hline 1 & $\begin{array}{l}4 \text { format pengaksesan: PDF Fulltext, HTML } \\
\text { Fulltext, Smart link, Abstract }\end{array}$ & 23 & 2,60 & 2,60 \\
\hline 2 & $\begin{array}{l}3 \text { format pengaksesan: (PDF Fulltext, HTML } \\
\text { Fullext, Abstract) atau (PDF Fullext, HTML } \\
\text { Fulltext, Smart link) }\end{array}$ & 123 & 13,93 & 16,53 \\
\hline 3 & $\begin{array}{l}2 \text { format pengaksesan (PDF Fulltext, Abstract) } \\
\text { atau (HTML Fulltext, Abstract) atau (PDF } \\
\text { Fulltext, Smart link) atau (PDF Fulliext, Smart } \\
\text { link) }\end{array}$ & 573 & 64,90 & 81,43 \\
\hline 4 & $\begin{array}{l}1 \text { format pengaksesan: PDF Fulltex atau } H T M L \\
\text { Fulltext alau Smart link atau Abstract saja }\end{array}$ & 146 & 16,53 & 97,96 \\
\hline 5 & Tidak diakses & 18 & 2,04 & 100 \\
\hline & Jumlah & 883 & & \\
\hline
\end{tabular}

Sumber: Otah data dari Usage Statistics Ebsco BRC, Agustus 2006 
Dari data tersebut kita bisa mengetahui bahwa prosentase terbesar yaitu $84,40 \%$ jurnal diakses kurang dari 100 kali selama satu tahun. Pengaksesan jurnal lebih dari 500 kali hanya sebesar $2,88 \%$. Hal ini berarti bahwa tingkat pengaksesan jurnal Ebsco BRC di UPIK belum maksimal.

Tabel 4.

\begin{tabular}{|c|c|c|c|c|c|}
\hline \multicolumn{6}{|c|}{ Frekuensi Pengguna dalam Men-doumload Jurnal } \\
\hline & & Frequency & Percent & Vatid Percent & $\begin{array}{c}\text { Cumulative } \\
\text { Percent }\end{array}$ \\
\hline \multirow[t]{6}{*}{ Valid } & Seflap Hari & 29 & 6,3 & 6,3 & 6,3 \\
\hline & 1 Minggu Sekali & 68 & 14,8 & 14,8 & 21,0 \\
\hline & 2 Minggu Sekali & 63 & 13,7 & 13,7 & 34,7 \\
\hline & Sebulan Sekali & 211 & 45,8 & 45,8 & 80,5 \\
\hline & $\begin{array}{l}\text { Tidak Perrah atau } \\
1 \text { Tahun Sekali }\end{array}$ & 90 & 19,5 & 19,5 & 100,0 \\
\hline & Tơal & 461 & 100,0 & 100,0 & \\
\hline
\end{tabular}

Sumber: Olah data, Agustus 2006

Total pengaksesan jurnal pada tahun 2005 sebanyak 80333 kali. Pengaksesan ini meliputi pengaksesan dengan format PDF Fulltext, HTML Fulltext, Image link, Custom link,Smart link dan Abstract. Dari data total pengaksesan selama tahun 2005 sebesar 80333 , rata-rata pengaksesan per bulannya sebanyak 6694 ratarrata pengaksesan per hari 223. Bila pengaksesan ini dibandingkan dengan total jurnal yang ada maka perbandingannya $223: 883=0,25$. Artinya bahwa dari total 883 judul jurnal yang ada hanya diakses sebesar $25 \%$ setiap harinya.

Kecilnya tingkat pengaksesan ini Bhisop (2006:4) mengidentifikasi ada beberapa sebab diantaranya:

1. Beberapa pengguna potensial tidak mengetahui tentang jurnal ini

2. Ada masalah dengan pengaksesannya baik dari faktor pengguna maupun faktor luar seperti fasilitas, konektivitas $\mathrm{dsb}$
3. Pengguna merasa malas dengan prosedur registrasi yang berbelit-belit

4. Jurnal yang tersedia tidak sesuai dengan kebutuhan pengguna saat itu.

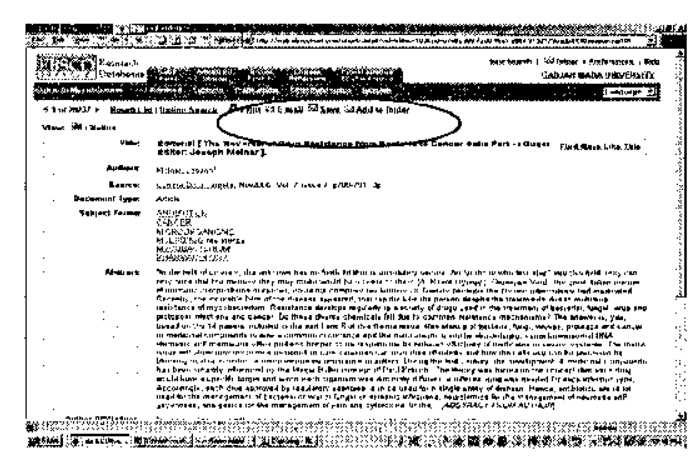

Gambar 1.Tampilan Halaman Hasil Penelusuran Ebsco BRC

Alasan lain mengapa pengaksesannya kecil adalah karena Ebsco BRC bukan satusatunya jurnal yang ada di UPIK. Masih ada database lain yaitu Proquest dan database Ebsco lain yang juga memungkinkan diakses dan digunakan sebagai sumber informasi dan sumber refernsi oleh pengguna UPIK, dan juga tersedianya alternative jurnal offline yang juga bisa dijadikan sebagai alternative sumber referensi bagi mahasiswa.

Berdasarkan data yang ada, pemakaian atau pengaksesan jurnal oleh pengguna hanya dilakukan melalui 4 bentuk pengaksesan yaitu PDF Fulltext, HTML Fulltext, Smart link dan Abstract. Pola pengaksesan jurnal Ebsco BRC sebagai berikut:

Dari keempat pola pengaksesan yang ada dapat diketahui bahwa $81,43 \%$ pengguna Ebsco BRC mengakses Fulltext yang diikuti dengan mengakses abstraknya. Hal ini menunjukkan bahwa peranan abstrak dalam sebuah jurnal sangat penting untuk bisa memberi pertimbangan kepada pengguna 
perlu atau tidaknya mengakses format fulltext jurnalnya.

Tabel 5.

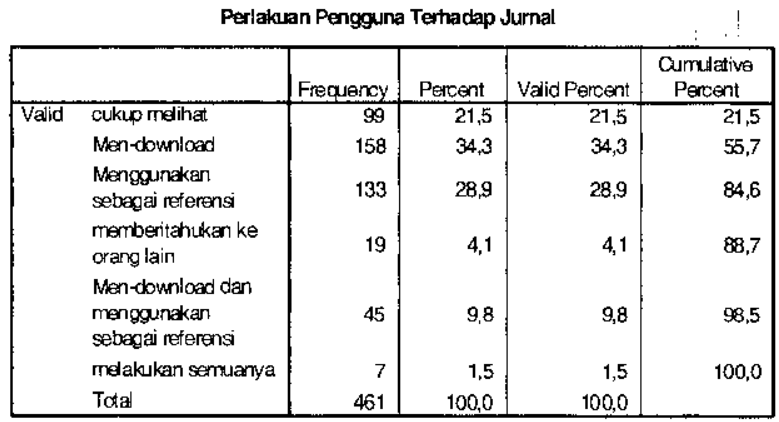

Sumber: Olah data, Agustus 2006

B. Pemanfaatan Jurnal dalam Database Ebsco BRC

Pemanfaatan jurnal dalam database Ebsco BRC bisa diartikan sebagai Material use yang dapat menunjukkan frekuensi penggunaan koleksi (Bhisop, 2006:5). Frekuensi pemanfaatan jurnal oleh pengguna berdasarkan data kuesioner yang disebarkan adalah sebagai berikut:

Dari hasil olah data dapat diketahui bahwa pengguna yang tidak pernah mendownload jurnal atau hanya satu tahun sekali men-download sebanyak 19,5\%. Frekuensi tertinggi dalam men-download jurnal dilakukan sebulan sekali oleh pengguna yaitu sebesar $45,8 \%$, disusul kemudian dengan satu minggu sekali sebesar $14,8 \%$, dua minggu sekali sebesar $13,7 \%$ dan hanya $6,3 \%$ pengguna yang melakukan download jurnal Ebsco setiap hari.

Prosentase responden sebesar 19,5\% yang menjawab tidak pernah atau 1 tahun sekali dikarenakan jurnal Ebsco BRC bukan satu-satunya database yang ada di UPIK UGM. Masih ada database jurnal lain yang juga bisa diakses secara online yaitu Proquest dan database online lain yang dilanggan oleh
Universitas (Business Source Premier /BSP dan Academic Search Premier/ASP). Keberadaan database ini memberikan akses informasi yang lebih luas bagi mahasiswa FK UGM pada umumnya dan pengguna UPIK pada khususnya.

Dari menu tampilan Ebsco kita bisa mengetahui bahwa ada 4 pilihan bagi pengguna dalam melakukan download terhadap jurnal yang dikehendakinya.yaitu: Print, E-mail, Save atau Add to Folder. Tampilan halaman hasil penelusuran serta menu download Ebsco BRC sebagai berikut:

Penyediaan pilihan menu-menu tersebut dimaksudkan untuk mempermudah bagi pengguna jika ingin men-download hasil penelusuran. Jadi dalam melakukan akses terhadap jurnal dalam Ebsco BRC pengguna tidak hanya bisa melihat melalui layar komputer saja akan tetapi pengguna juga dapat menyimpan jurnal tersebut baih dalam bentuk tercetak maupun dalam bentuk file.

Sebagai bahan evaluasi kita juga perlu mengetahui penggunaan jurnal selain didownload atau penggunaan jurnal setelah jurnal itu didownload. Melalui survey yang dilakukan terhadap pengguna, perlakuan mereka terhadap jurnal Ebsco BRC dapat dilihat pada tabel 5 .

Dari data tersebut dapat diketahui prosentase hal yang paling banyak dilakukan pengguna terhadap jurnal Ebsco BRC adalah men-download jurnal tersebut dalam bentuk file ataupun mencetak (print-out) yaitu sebesar $34,3 \%$. Dari data yang disajikan juga dapat diketahui bahwa sebanyak $28,9 \%$ pengguna menggunakan jurnal Ebsco BRC sebagai rujukan dan $9,8 \%$ pengguna melakukan 
download sekaligus menggunakannya sebagai rujukan. Namun demikian ada juga pengguna yang hanya melihat/membaca jurnal tersebut tanpa melakukan download yaitu sebesar 21,5 $\%$, sebanyak $9,8 \%$ pengguna memberitahukan jurnal tersebut kepada orang lain dan hanya $1,5 \%$ pengguna yang melakukan semuanya baik melihat, download, menggunakan sebagai rujukan maupun memberitahukan kepada orang lain.

Besarnya prosentase kumulatif antara kegiatan download dan penggunaan jurnal sebagai rujukan menunjukkan bahwa jurnal yang ada di dalam database Ebsco BRC sesuai kebutuhan pengguna UPIK. Walaupun tidak semua pengguna menggunakan jurnal tersebut akan tetapi jurnal yang ada tetap diakses dan digunakan sebagai referensi. Pengguna Jurnal online ini terutama adalah mahasiswa yang akan menyelesaikan tugas akhir baik itu skripsi untuk program S1 maupun tesis untuk program S2. Namun bukan berarti bahwa mahasiswa baru tidak memanfaatkan jurnal ini. Kebanyakan dari mahasiswa semester awal memanfaatkan jurnal untuk mengerjakan tugas mata kuliah yang diberikan oleh dosen masing-masing.

Terkait dengan pemanfaatan ini beberapa hal yang perlu juga digunakan sebagai bahan evaluasinya adalah:

\section{Pengenalan atau sosialisasi Jurnal}

Sosialisasi merupakan langkah awal dari sukses atau tidaknya pemasaran sebuah produk. Dalam hal ini jurnal Ebsco BRC adalah produk layanan yang dimiliki oleh UPIK yang harusnya dapat dimaksimalkan penggunaannya. Untuk dapat memanfaatkannya maka perlu adanya pengenalan atau sosialisasi terhadap produk tersebut agar konsumen dapat menyesuaikan produk yang ditawarkan dengan kebutuhan mereka. Pengenalan atau sosialisasi jurnal Ebsco BRC terhadap pengguna berdasarkan pendapat pengguna terhadap pernyataan "Anda mengetahui Database Ebsco BRC yang dilanggan oleh UPIK FK UGM". Hasil perolehan data kuesioner menyatakan bahwa $57,9 \%$ pengguna menyatakan setuju atau mengetahui, $18 \%$ menyatakan sangat setuju atau sangat mengetahui, $10,6 \%$ menyatakan tidak berpendapat, $11,1 \%$ tidak setuju atau tidak mengetahui dan 2,4\% menyatakan sangat tidak setuju atau sangat tidak mengetahui database Ebsco BRC.

Dari data tersebut juga bisa diketahui bahwa sebanyak $13,5 \%$ responden menyatakan tidak mengetahui database Ebsco BRC. Hal ini dapat menjadi hambatan tersendiri bagi maksimalisasi pemanfaatan koleksi tersebut. Bagaimana pengguna akan memanfaatkan koleksi jika dia tidak mengeahui koleksi tersebut tersedia di perpustakaan. Karena itu perlu kiranya dikaji ulang tentang sosialisasi Ebsco BRC ke pengguna agar koleksi tersebut dapat dimanfaatkan secara maksimal. Berkaitan dengan sosialisasi ini wakil Ebsco melakukan pelatihan penelusuran database secara berkala kepada staff pengajar FK UGM. Bagi para mahasiswa pelatihan dilakukan satu tahun sekali yang diberikan oleh petugas perpustakaan kepada mahasiswa baru (Laporan ketua UPIK 2005, 2006:13).

Frekuensi sosialisasi untuk mahasiswa yang hanya 1 kali satu tahun ini mungkin sangat kurang bagi mahasiswa, karena mahasiswa tidak akan cukup memahami banyaknya layanan yang tersedia di perpustakaan dengan satu kali pengenalan 
saja. Namun sebenarnya dalam mata kuliah blok yang dijalankan oleh Fakultas Kedokteran UGM ada 2 blok yang memungkinkan untuk memperkenalkan jurnal-jurnal dalam database ini. Blok mata kuliah yang dimaksud yaitu Blok I tentang Study Skills and Information Technology yang diberikan selama 6 minggu dan Blok XIII tentang Medical Science And Technology yang diberikan selama 7 minggu. Pemanfaatan blok mata kuliah ini sangat penting untuk melakukan sosialisasi terhadap database Ebsco untuk memaksimalkan penggunaannya. Akan tetapi satu hal yang menjadi kelemahan sistem blok ini, bahwa yang menganut perkuliahan dengan sistem blok hanya mahasiswa untuk program S1 Pendidikan dokter saja, sedangkan untuk program studi lainnya tetap diperlukan sosialisasi secara tersendiri.

Dari pertanyaan tentang sosialisasi Ebsco oleh UPIK diketahui bahwa 37,5\% pengguna menyatakan setuju, 2,6\% menyatakan sangat setuju, 20\% menyatakan tidak berpendapat, 34,5\% menyatakan tidak setuju dan $5,4 \%$ menyatakan sangat tidak setuju dengan pernyataan bahwa sosialisasi koleksi jurnal dalam database online Ebsco BRC dilakukan dengan Baik.

Berimbangnya antara jawaban responden yang positif dan negatif tentang sosialisasi Ebsco BRC dapat menjadi masukan bagi UPIK untuk menambah frekuensi sosialisasi yang dilakukan, terutama untuk mensosialisasikan adanya database ini dan materi jurnal yang terdapat didalamnya. Sebagai bahan perbandingan tentang pengenalan pengguna terhadap Ebsco BRC, maka dimunculkan pertanyaan tentang bagaimana pendapat pengguna mengenai tampilan Ebsco BRC. Apabila pengguna merasa tahu atau pernah merasa mengenal database ini diharapkan mereka akan memberikan pendapat tentang database tersebut, walaupun prosentase jawaban "tidak berpendapat" sebesar 23,6\%. Selalu munculnya jawaban ini memang merupakan satu kelemahan penelitian ini, karena jawaban ini sulit diinterpretasikan dalam analisis penelitian ini.

Tabel 6.

\begin{tabular}{|c|c|c|c|c|c|}
\hline & & Frequency & Percent & Vaird Percent & $\begin{array}{l}\text { Cominative } \\
\text { Percent }\end{array}$ \\
\hline \multirow[t]{8}{*}{ Vall } & Kompiter & 256 & $\overline{55,5}$ & 55,5 & 55,5 \\
\hline & Laptop pribad & 51 & 11,1 & 11,1 & 66,6 \\
\hline & $\begin{array}{l}\text { Internet dilinghurgan } \\
\text { Fakultas Keddhteran }\end{array}$ & 11 & 24 & 2,4 & 69,0 \\
\hline & $\begin{array}{l}\text { Intrangt didaiam } \\
\text { Fakuttas Keddkteran }\end{array}$ & 94 & 20,4 & 20,4 & 89,4 \\
\hline & $\begin{array}{l}\text { Kompler UPK } \\
\text { Leptop }\end{array}$ & 23 & 5,0 & 5,0 & 94,4 \\
\hline & $\begin{array}{l}\text { Komouter UPAK } \\
\text { hitrenet }\end{array}$ & 25 & 5,4 & 5,4 & 99,8 \\
\hline & $\begin{array}{l}\text { Kompler } \\
\text { Laptopden Intrand }\end{array}$ & 1 & , 2 & 2 & 100,0 \\
\hline & Tolal & 461 & 100,0 & 1000 & \\
\hline
\end{tabular}

Sumber: Olah data, Agustus 2006

Pendapat pengguna terhadap tampilan Ebsco BRC berdasarkan data perolehan dari kuesioner bahwa $54 \%$ pengguna menyatakan setuju, 5,9\% pengguna menyatakan sangat setuju, 23,6\% menyatakan tidak berpendapat, $15,8 \%$ menyatakan tidak setuju dan $0,7 \%$ menyatakan sangat tidak setuju dengan penyataan bahwa tampilan database Ebsco BRC cukup baik. Dengan demikian bisa dikatakan bahwa berdasarkan pendapat penggunana tampilan Ebsco BRC cukup baik. Dengan demikian tidak ada masalah dengan tampilan jurnal Ebsco.

\section{Fasilitas}

Pengaksesan jurnal Ebsco BRC secara online dilayankan oleh UPIK dengan menyediakan 32 unit komputer untuk mengakses jurnal dan juga layanan wifi untuk pengguna yang menggunakan laptop. Berdasarkan data survey yang dilakukan 
melalui kuesioner tentang fasilitas dan kondisi peralatan yang ada di UPIK diketahui bahwa $42,5 \%$ pengguna menyatakan tidak setuju, $10 \%$ menyatakan sangat tidak setuju, 13,4\% menyatakan tidak berpendapat, $30,2 \%$ menyatakan setuju dan 3,9\% menyatakan sangat setuju dengan pernyataan bahwa perbandingan jumlah komputer yang tersedia di UPIK FK UGM dengan pengguna yang mengakses Ebsco mencukupi. Dari data tersebut bisa diartikan bahwa jumlah komputer di UPIK belum mencukupi untuk memenuhi kebutuhan mahasiswa dalam mengakses database online. Karena itu mungkin perlu adanya penambahan jumlah komputer bagi pengguna agar tidak terjadi antrian komputer di ruang internet UPIK untuk mengakses jurnal ini.

Penyediaan fasilitas komputer di UPIK berkaitan dengan jalur yang digunakan oleh pengguna dalam mengakses Ebsco, karena pengaksesan Ebsco BRC tidak harus dilakukan di UPIK. Dalam hal ini pengaksesan database Ebsco dapat dilakukan melalui tempat lain asal terkoneksi dengan internet dan nomor IP address-nya sudah diregistrasikan pada pihak pelanggan jurnal (UPIK). Hal ini dilakukan untuk memudahkan bagi admin di UPIK dalam pengontrolan dan mengetahui siapa saja yang mengakses jurnal dan jumlah pengaksesan yang mereka lakukan. Tentu saja hal ini merupakan sesuatu yang penting untuk dilakukan karena penyedia layanan berhak tahu siapa saja yang memanfaatkan layanan yang ditawarkan tersebut, termasuk layanan dalam penggunaan jurnal online Biomedical Reference Collection ini.
Dari data kuesioner yang disebarkan tentang cara pengguna mengakses jurnal Ebsco $\mathrm{BRC}$ didapatkan data-data: 55,5\% responden menyatakan mengakses Ebsco BRC melalui komputer UPIK, 20,4\% melalui intranet Fakultas Kedokteran, 11,1\% melalui Laptop pribadi, 5,4\% menyatakan melalui komputer UPIK dan intranet, $5 \%$ melalui komputer UPIK dan Laptop, 2,4\% melalui internet dilingkungan FK UGM dan 0,2\% melalui Laptop dan Intranet dalam FK UGM. Data hasil kuesioner tentang cara pengguna dalam mengakses jurnal Ebsco BRC disajikan dalam Tabel 6.

Penyediaan fasilitas harus disertai dengan perawatan dari fasilitas tersebut. Berkaitan dengan hal itu, kondisi fasilitas komputer yang ada di UPIK 62,7\% responden menyatakan setuju, 5,4\% menyatakan sangat setuju, 13,7\% menyatakan tidak berpendapat, $17,6 \%$ menyatakan tidak setuju dan hanya $0,7 \%$ responden yang menyatakan sangat tidak setuju terhadap pernyataan bahwa fasilitas komputer yang disediakan oleh UPIK FK UGM dalam kondisi baik dan bisa digunakan. Hal ini berarti bahwa fasilitas komputer yang ada dapat digunakan dengan baik.

\section{Aksesibilitas}

Aksesibilitas sebuah informasi dapat dilihat dari kemudahan dan kecepatan data tersebut diakses. Aksesibilitas ini merupakan faktor utama yang menjadi pertimbangan pengguna dalam pengaksesan secara online. Pengguna akan merasa jenuh dan akhirnya enggan menggunakan fasilitas secara online bila menunggu koneksi atau proses penelusuran yang terlalu lama. Aksesibilitas database secara online dapat ditinjau dari beberapa hal: 
Tabel. 7

Cara Pengguna Mempe roleh informasi Pengaksesan Ebsco

\begin{tabular}{|c|c|c|c|c|c|}
\hline & & Frequency & Percent & Valid Percent & $\begin{array}{c}\text { Cummulative } \\
\text { Percent }\end{array}$ \\
\hline \multirow[t]{7}{*}{ Valid } & Otodidak & 208 & 45,1 & 45,1 & 45,1 \\
\hline & $\begin{array}{l}\text { Menggunakan } \\
\text { Petunjuk Ebsco }\end{array}$ & 71 & 15,4 & 15,4 & 60,5 \\
\hline & $\begin{array}{l}\text { Mengikuti Pelatihan } \\
\text { dari Ebsco }\end{array}$ & 10 & 2,2 & 2,2 & 62,7 \\
\hline & $\begin{array}{l}\text { Bimbingan } \\
\text { Perpustakaan UPIK }\end{array}$ & 146 & 31,7 & 31,7 & 94,4 \\
\hline & $\begin{array}{l}\text { Otodidak dan } \\
\text { Bimbingan dari UPIK }\end{array}$ & 22 & 4,8 & 4,8 & 99,1 \\
\hline & $\begin{array}{l}\text { Otodidak dan } \\
\text { menggunakan } \\
\text { petunjuk Ebsco }\end{array}$ & 4 & ,9 & .9 & 100,0 \\
\hline & Total & 461 & 100,0 & 100,0 & \\
\hline
\end{tabular}

Sumber: Olah dato, Agustus 2006

1. Dari kecepatan koneksi internet (bandwith) yang dimiliki oleh jaringan di UPIK FK UGM. Kecepatan koneksi ini sangat mempengaruhi lamanya proses penelusuran yang sedang berlangsung. Dengan kecepatan 1 Mbps merupakan ukuran bandwith yang besar bagi pengaksesan internet secara umum.

2. Dari cara/sistem penelusuran yang dipilih oleh pengguna. Cara penelusuran ini akan menentukan hasil yang akan diperoleh nantinya. Dari menu penelusuran Ebsco ada tiga cara penelusuran yang dapat dilakukan yaitu: Basic Search, Advance Search dan Visual Search.

3. Ketrampilan pengguna dalam menggunakan internet akan sangat berpengaruh bagi aksesibilitas ini. Pengguna yang sudah terbiasa menggunakan internet biasanya akan lebih cepat menemukan informasi yang dibutuhkan daripada pengguna yang tidak terbiasa menggunakan internet.
Dari data kuesioner yang disebarkan kepada responden tentang aksesibilitas Ebsco dan kemudahan pengaksesan Ebsco didapatkan data $48,6 \%$ responden yang menyatakan setuju dan $1,1 \%$ yang menyatakan sangat setuju. Pendapat lainnya $22,6 \%$ responden menyatakan tidak berpendapat, 24,7\% menyatakan tidak setuju dan $3 \%$ responden menyatakan sangat tidak setuju dengan pernyataan bahwa "Pengaksesan jurnal dalam database online Ebsco dapat dilakukan dengan mudah". Dari data tersebut disimpulkan bahwa pengaksesan Ebsco tidak cukup mudah dilakukan.

Perolehan informasi pada saat mengakses database Ebsco tidak dapat cepat dilakukan. Hal ini ditunjukkan oleh perolehan data dari pernyataan pendapat responden terhadap pernyataan: informasi tentang jurnal yang ingin diakses dalam database Ebsco dapat diakses dengan cepat. Dari data hasil kuesioner diketahui bahwa 39\% responden menyatakan setuju dan $1,7 \%$ responden menyatakan sangat setuju, 22,1\% menyatakan tidak berpendapat, $32,8 \%$ menyatakan tidak setuju dan $4,3 \%$ menyatakan sangat tidak setuju.

Kedua perolehan data aksesibilitas diatas menunjukkan bahwa aksesibilitas database Ebsco BRC tidak mudah dilakukan dan proses penelusurannya cukup lama. Hal ini tentu saja membuat nilai database ini sedikit menurun karena pengguna tidak dapat segera mendapatkan informasi yang diinginkan, padahal dengan adanya fasilitas searching secara online pengguna berharap dapat 
mengakses informasi dengan cepat dan tepat. Yang perlu disadari betul adalah ketiga hal yang mempengaruhi aksesibilitas yang sudah diuraikan sebelumnya. Apakah ketiga hal tersebut sudah dilakukan dengan baik atau belum. Jika memang ada salah satu yang kurang mungkin inilah yang menjadi faktor penyebab dari kelambatan dan kesulitan yang dialami.

Jika memang ketiga faktor tersebut sudah dipenuhi akan tetapi aksesibilitasnya tetap sulit mungkin ada faktor lain seperti jumlah pengakses yang banyak dalam waktu yang bersamaan atau file yang diakses melebihi kapasitas yang disediakan, dan sebagainya.

4. Penguasaan Teknologi informasi oleh pengguna:

Pengaksesan jurnal secara online tak bisa dilepaskan dari penguasaan teknologi informasi atau internet oleh responden. Hal ini karena banyak sekali menu-menu yang bisa dimanfaatkan oleh pengguna. Untuk itu penguasaan TI oleh pengguna perlu menjadi bahan evaluasi bagi pemanfaatan jurnal yang ada. Data tentang penguasaan teknologi informasi menurut survei terhadap responden dapat diketahui 56,4\% responden merasa mahir dalam menggunakan internet dalam mencari informasi, 9,1\% merasa sangat mahir, 17,6 menyatakan tidak berpendapat, $15,8 \%$ menyatakan tidak mahir dan hanya $1,1 \%$ yang merasa sangat tidak mahir. Hal ini berarti bahwa responden mempunyai ketrampilan internet yang cukup sebagai bekal dalam pengaksesan database online Ebsco.

Pengaksesan jurnal secara online tidak semudah pengaksesan jurnal tercetak. Ada cara-cara tertentu yang digunakan untuk mendapatkan informasi yang tepat. Karena itu perlu adanya bimbingan atau pelatihan bagi pengguna dalam pengaksesannya, namun demikian bagi pengguna yang sudah biasa dengan internet hal itu bisa dipelajari secara otodidak atau mengikuti petunjuk online dari administrator. Dari data kuesioner prosentase cara pengguna memperoleh informasi pengaksesan Ebsco BRC disajikan dalam Tabel 7.

Dari data tersebut diatas dapat diketahui bahwa $45,1 \%$ responden memperoleh informasi cara pengaksesan Ebsco secara otodidak, $31,7 \%$ responden merasa mendapatkan bimbingan dari UPIK, 15,4\% menggunakan petunjuk online dari Ebsco, 4,8\% otodidak dan melalui bimbingan dari UPIK, 2,2\% mengikuti pelatihan dari Ebsco dan 0,9 persen yang melakukannya secara otodidak dan menggunakan petunjuk dari Ebsco.

Prosentase jawaban responden yang cukup merata menunjukkan bahwa tidak ada satu metode yang mendominasi dalam menentukan cara perolehan informasi pengaksesan terhadap jurnal tersebut. Artinya pengguna bisa saja mengkombinasikan berbagai cara untuk mendapatkan informasi yang sejelas-jelasnya tentang bagaimana cara mengakses Ebsco. Akan tetapi lebih tingginya pengguna yang merasa melakukan otodidak dapat dipakai sebagai data untuk menyarankan UPIK agar meningkatkan layanan bimbingan perpustakaan dalam hal ini.

\section{Core Jurnal dalam Basis Data Ebsco BRC}

Core jurnal adalah jurnal yang paling sering diakses oleh pengguna. Berdasarkan data usage statistics report ada 12 judul jurnal yang pengaksesannya lebih dari 1000 kali. Judul 
jurnal yang dimaksud adalah: Journal of Bone E Joint Surgery (American Volume), Nursing, Lancet, Perfusion-Sevenoaks, Pediatrics, British journal of Sourgery, BMJ, AIDS Patient Care ESTDS, Journal of Infectious Disease, Nursing Management, Geriatrics dan American Family Phisician. Jurnal-jurnal tersebut ditentukan sebagai jurnal inti berdasarkan tingkat pengaksesan yang tertinggi yaitu lebih dari 1000 kali.

Pengaksesan yang tinggi yaitu antara 500-1000 kali terjadi pada 13 judul jurnal berikutnya. Jadi bisa disampaikan disini bahwa ada 12 judul jurnal dengan pengaksesan tertinggi dan 13 judul jurnal yang pengaksesannya tinggi.

\section{KESIMPULAN DAN SARAN}

Dari berbagai uraian dan data-data yang dikumpulkan, maka dapat diambil kesimpulan sebagai berikut:

1. Tingkat keterpakaian jurnal Ebsco BRC sebesar 97,96\%. Prosentase ini terbagi dalam 4 bentuk penyajian yaitu: PDF Fulltext, HTML Fulltext, Smart link dan Abstract. Pengaksesan terbesar berturut-turut adalah format PDF, Abstrak, HTML dan smart link.

2. Pemanfaatan atau pengaksesan jurnal Ebsco BRC oleh pengguna UPIK belum maksimal. Dari nilai rata-rata pengaksesan jurnal Ebsco BRC setiap harinya dibandingkan dengan total judul jurnal yang tersedia prosentasenya sebesar $25 \%$. Hal ini didukung oleh hasil perolehan data kuesioner yang menyatakan bahwa sebanyak $45,8 \%$ responden men- download jurnal 1 bulan sekali dan $19,5 \%$ responden merasa tidak pernah atau 1 tahun sekali men-download jurnal tersebut.

3. Berdasarkan prosentase jawaban responden terhadap pertanyaanpertanyaan yang berkaitan dengan sosialisasi, aksesibilitas fasilitas dan penguasan teknologi informasi oleh pengguna, belum maksimalnya pemanfaatan jurnal Ebsco BRC ini karena:

a.Pengenalan/sosialisasi terhadap jurnal ini belum maksimal

b.Fasilitas komputer dalam kondisi baik tetapi belum mencukupi

c. Aksesibilitas Ebsco BRC lambat dan pengaksesan jurnal yang terdapat didalamnya tidak mudah dilakukan

d.Meskipun penguasaan teknologi informasi / internet pengguna sudah bagus tetapi harus tetap ada bimbingan dan pelatihan agar informasi yang dimaksud dapat cepat ditemukan dan sesuai dengan kebutuhan oleh pengguna.

4. Dari penentuan core jurnal, ada 12 judul jurnal yang sering diakses oleh pengguna dengan jumlah pengaksesan tertinggi yaitu lebih dari 1000 kali yang terdiri dari: Journal of Bone E Joint Surgery (American Volume), Nursing, Lancet, Perfusion-Sevenoaks, Pediatrics, British journal of Sourgery, BMJ, AIDS Patient Care ESTDS, Journal of Infectious Disease, Nursing Management, Geriatrics dan American Family Phisician. Jumlah 
core jurnal mencapai 25 bila jurnal dengan pengaksesan tinggi yaitu antara 500-1000 kali diikutsertakan dalam penghitungan core-nya.

Dari beberapa kesimpulan diatas kita bisa mengambil intisarinya bahwa meskipun tingkat keterpakaian jurnal berdasarkan judulnya sebesar 97,96\% akan tetapi bila dilihat dari tingkat pengaksesannya masih kurang. Karena itu untuk memaksimalkan jurnal Ebsco BRC penulis menyarankan untuk:

1. Lebih meningkatkan sosialisasi tentang keberadaan jurnal ini kepada pengguna potensial yaitu seluruh sivitas akademika di lingkungan Fakultas Kedokteran UGM. Semakin banyak orang yang mengetahui keberadaan jurnal dalam database ini diharapkan dapat memaksimalkan penggunaannya.

2. Menambah fasilitas komputer untuk pengaksesan jurnal. Meskipun pengaksesan jurnal dapat dilakukan di tempat lain akan tetapi dengan menyediakan fasilitas yang lebih banyak maka akan menambah kesempatan pengguna yang ingin mengakses jurnal.

3. Meningkatkan frekuensi bimbingan pengaksesan jurnal pada pengguna potensial terutama pada mahasiswa, sehingga pengguna dapat melakukan penelusuran dengan lebih mudah dan dengan cara ini diharapkan pengguna dapat memperoleh informasi lebih cepat dan lebih tepat.

4. UPIK tetap melanggan jurnal ini dengan mempertimbangkan ketiga saran tersebut diatas.

\section{DAFTAR PUSTAKA}

Anonim. 2006. Laporan Dekan. Yogyakarta: Fakultas Kedokteran UGM

Arikunto, Suharsimi. 2002. Prosedur Penelitian:

Suatu Pendekatan Praktek. Ed. Revisi V. Jakarta: Rineka Cipta

Bishop, Ann Peterson. Measuring Access, Use and Success In Digital Libraries. Diakses melalui http://paracite.eprints.org/cgi-bin... Tanggal 16 Agustus 2006 pukul 10.00WIB.

Effendi, Sofian. 1989. „Prinsip-prinsip Pengukuran dan Penyusunan Skala" dalam Metode Penelitian Survey. Editor: Masri Singarimbun, Jakarta: LP3ES

Elnumeri, Farli. 2002. Analisis Pemanfaatan Koleksi Perpustakaan Pramuka Ki Hajar Dewantara. Jurusan Ilmu Perpustakaan Fakultas Ilmu Budaya Universitas Indonesia Jakarta.

Evans.G. E. 1995. Developing Library And Information Center Collections. Third Ed. Colorado: Libraries Unlimited.

Evens, Bob. 1996. "The Effect Of Recent Developments In University Libraries On The Research Proses" dalam "Modernizing Research Libraries". United of Kingdom: British Library

Gorman, G.E. 1989. Collection development For Library. London: Bowker-Saur

Hardi, Wisnu. 2005. "Kajian Koleksi Bidang Linguistik Dengan Metode Conspectus di Perpustakaan FIB UI" diakses melalui http:/ /conspectusmodel.tripod.com/ tanggal 4 Februari pukul 14.30 WIB 
IFLA. 2001."Guidelines For A Collection Development Policy Using The Conspectus Model. 2001". Ifla \& Institution Section on Acquisition And Collection development diakses melalui http://www.ifla.org/VIII/ 514/nd1/gdcp e.pdf tanggal 4 Februari pukul 16.15 WIB

Ishak. 2001. Evaluasi Pemanfaatan Koleksi Majalah ilmiah di Pusat Kedokteran (Medical Information Center) P.T. Squibb Indonesia. Jurusan Ilmu Perpustakaan Fakultas Ilmu Budaya Universitas Indonesia Jakarta.

Kamus Besar Bahasa Indonesia. 2005. Pusat Bahasa Departemen Pendidikan Nasional. Jakarta: Balai Pustaka

Law, Derek. 1991. "The Organization Of Collection management in Academic Libraries" dalam Collection Management in Academic Libraries. England: Gower Publishing Limited

Mustafa, B. 1998. "Perubahan Paradigma Layanan Perpustakaan Memasuki era Teknologi Informasi" dalam Dinamika Informasi Dalam Era Globalisasi. Bandung: Rosda Karya.

Nawawi, Hadari. 2003. Metode Penelitian Bidang Sosial. Yogyakarta: Gadjah Mada University Press

Norkman, Helen M. 1991. "The Influence of The Library User on Collection Management", dalam Collection Management in Academic Libraries. England: Gower Publishing Limited.

Ratnaningsih. 1998. "Pemberdayaan Perpustakaan Dan Pustakawan Menjelang Abad 21", dalam Dinamika Informasi dalam Era Globalisasi Bandung: Rosda Karya.
Reitz, Joan M. 2006."Online Dictionary in Library Science". Dalam http://lu.com/ odlis/index.cfm, tanggal 25 Februari 2006, pukul 14.00 WIB

Thompsom, James. 1982. The End Of Libraries. London: Clive Bingley 